\title{
O CONSTITUCIONALISMO ATRAVÉS DO CONFLITO - UMA REFLEXÃO E ALGUNS COMENTÁRIOS EM TORNO DA IDEIA DE CONSTITUIÇÃO RADICAL
}

\author{
THE CONSTITUTIONALISM THROUGH THE CONFLICT - A REFLECTION AND \\ A FEW REMARKS REGARDING THE IDEA OF RADICAL CONSTITUTION
}

\author{
Leonardo Monteiro Crespo de Almeida*
}

RESUMO: este artigo pretende discutir e desenvolver alguns pontos referentes à ideia de Constituição radical, apresentada pela professora Vera Karam de Chueiri em seu artigo Constituição radical: uma ideia e uma prática. Com o auxílio de alguns conceitos extraídos da obra de Jacques Rancière, destacamos como o referido conceito de Constituição poderia assimilar conflitos políticos sem comprometer as conquistas consolidadas pelos vários movimentos sociais e os direitos das minorias políticas. Discutimos, ao final, como a ideia de Constituição radical poderia ser frutífera para o pensamento da interdependência complexa e tensa entre constitucionalismo e democracia, que também se mostra crucial para o trabalho de Vera Karam.

PALAVRAS-CHAVE: Agonismo. Constitucionalismo. Democracia. Rancière.

ABSTRACT: This article intends to discuss and develop some points regarding the idea of radical Constitution, introduced by Vera Karam de Chueiri in her article Radical Constitution: an idea and a practice. Taking a few concepts from Jacques Rancière's work, we emphasize how that concept of Constitution could develop a positive relation with political conflicts without risking the many achievements of social movements and the rights of political minorities. Finally, we discuss how the idea of radical Constitution could be productive in thinking the complex, difficult interdependence between constitutionalism and democracy, something that is also crucial for Chueiri's work.

KEYWORDS: Agonism. Constitutionalism. Democracy. Rancière.

\section{INTRODUÇÃO}

No volume 58 da Revista da Faculdade de Direito da Universidade Federal do Paraná (UFPR), disponibilizado no ano de 2013, a professora Vera Karam de Chueiri publicou um artigo no qual apresenta uma perspectiva teórica para que pensemos os atuais impasses do constitucionalismo contemporâneo - a de uma Constituição radical. Em um país cuja produção nesta área não tem sido marcada por maiores sofisticações teóricas, o referido artigo se mostrou uma grande exceção à regra, ao apresentar, desenvolver e confrontar autores muito

\footnotetext{
* Doutorando em Direito pela Faculdade de Direito do Recife/UFPE. Mestre em Direito pela Faculdade de Direito do Recife/UFPE. Bacharel em Direito pela AESO. Bacharel em Filosofia pela UFPE. Revista da Faculdade de Direito - UFPR, Curitiba, vol. 59, n. 3, p. 167-196, 2014.
} 
importantes para a teoria política contemporânea, mas que na área jurídica ainda aguardam leituras mais cuidadosas, como é o caso de Antônio Negri e de Chantal Mouffe.

Em meio a um panorama social brasileiro que envolve protestos coletivos e revoltas perante as várias promessas não cumpridas pelo poder público, ponderar a radicalidade da ação política mediada pela ideia, que também fora radical, de Constituição, é um exercício teórico difícil mas importante para os juristas que possuam um mínimo de sensibilidade aos enormes problemas sociais brasileiros.

$\mathrm{Na}$ interpretação que fazemos do trabalho de Vera Karam de Chueiri, a ideia de Constituição radical é conectada ao potencial de autotransformação interna da comunidade: refletem mudanças que não podem ser realizadas no plano normativo, nem a ele se resumem. Quando a autora introduz uma distinção entre a ideia de Constituição e as suas manifestações normativas e concretas (as Constituições positivas, como a Constituição brasileira e a norteamericana), assim o faz para ressaltar o conjunto de possibilidades presentes na ordem social, mas que permanecem ainda inexploradas. Evita-se incorrer mais uma vez em debates circunscritos aos processos de constitucionalização de direitos, ao mesmo tempo que se retomam as raízes políticas da ideia de Constituição por meio dos conflitos políticos.

A radicalidade dessa concepção teórica de Constituição, no trabalho de Chueiri, aponta para um duplo posicionamento em que a influência de autores pós-estruturalistas se faz notória: a absorção para si do caráter antagônico que marca o político e uma abertura temporal por meio da qual os fundamentos da Constituição permanecem indeterminados, abertos a um futuro, uma Constituição por vir, se assim podemos nomeá-la.

Pretendemos neste artigo desenvolver uma leitura em torno dessa temática, tendo como perspectiva teórica principal certos conceitos extraídos da obra de Jacques Rancière a respeito da ideia de democracia, especificamente os de democracia, do par polícia/política, de consenso e de conflito. A opção pela autora se deve, dentre outros motivos, à sua contínua preocupação com o conflito e com as transformações políticas substanciais, que se mostram em oposição às tímidas reformas que se tornaram características da maior parte das democracias liberais contemporâneas: a primeira característica de uma política verdadeiramente radical é a preocupação com mudanças profundas (MOUFFE, 2000, p. 121). Várias soluções administrativas acabam por modificar muitos aspectos do social apenas para que tudo permaneça como antes. Não é de se espantar com o nível de despolitização da sociedade brasileira, historicamente colocada sempre às margens dos grandes centros responsáveis pela tomada de decisões políticas significativas: em um panorama como o descrito, há o risco de se converter a pulsante ideia de democracia em um componente 
retórico de justificação do status quo. Por outras razões, Todd May observa também um certo grau preocupante de despolitização da sociedade norte-americana (MAY, 2008, p. 1 et seq.).

A abertura da Constituição aos conflitos políticos, que representam não apenas o embate de forças antagônicas, mas também visões díspares sobre as relações sociais, coloca-a em proximidade com as frustrações e necessidades da população que há muito tempo permanecem ignoradas, embora ainda se insista em dizer que a democracia é um governo feito pela e para a população. Quando Chueiri contrapõe a ideia de Constituição radical à linguagem normativa do constitucionalismo, a pretensão não é outra senão a de evitar fechar o futuro aos compromissos firmados no passado, uma exigência liberal em torno do controle racional do exercício do poder. Os conceitos de agonismo e antagonismo, tal como aparecem na obra de Chantal Mouffe, são importantes nesta temática, na medida em que possibilitam pensar o conflito político como elemento crucial para o advento e transformação das democracias liberais, sem expor a risco os direitos e garantias individuais já consolidados. Mouffe é, sem dúvida, a segunda mais importante influência teórica para este trabalho.

Em uma conjuntura política em que os mais variados segmentos políticos mostramse a favor da democracia, esta acaba por se tornar um consenso político inquestionável, um dogma, cujo verdadeiro sentido, talvez, nada tem de democrático. Seria a Primavera Árabe uma irrupção antidemocrática, perigosa, ou, talvez, um dos poucos resquícios de democracia presentes em um mundo profundamente antidemocrático?

Iniciaremos o artigo a partir de uma análise acerca da forma com que Rancière repensa o conceito de democracia, para além de um ideal normativo de política governamental, uma forma de Estado que sociedades desenvolvidas devem adotar, inclusive para fomentar e manter o crescimento econômico. Esse ponto compreende toda a primeira seção. Na seção posterior utilizaremos os conceitos de polícia e política tal como o autor os concebe, para pensarmos a importância do conflito na democracia, principalmente como alternativa a um suposto ideal tecnocrático de política que não só aliena a população como também torna a política o espaço por excelência de uma racionalidade estratégica e comprometida apenas com o presente estado das coisas (CHUEIRI, 2003, p. 31).

A função da terceira seção consiste em unir as reflexões oriundas de nossa leitura seletiva da obra de Rancière com a ideia de Constituição radical. A dinâmica das relações políticas de inclusão e exclusão, bem como a desestabilização da ordem social, são os dois pontos que buscaremos destacar. Os dois se conectam com a preocupação em transformar as condições precárias das minorias políticas e com o papel que a Constituição, em um regime democrático, pode assumir neste processo. Identificamos no trabalho de Vera Karam uma 
preocupação com os direitos dos grupos excluídos que também é a nossa, e o propósito desta seção foi justamente o de tentar desenvolver essa conexão.

Por fim, a quarta seção lida diretamente com a relação complexa entre constitucionalismo e democracia, ou soberania popular. Evitando-se reduzir um termo ao outro, buscaremos compatibilizar o conflito político e o dissenso, elementos que consideramos de grande importância para o aprofundamento da democracia, com a proteção que o constitucionalismo, enquanto teoria do poder limitado, dá às conquistas consolidadas após um histórico de lutas e embates por novos direitos e garantias. Longe de ser uma resposta para esse embate ou sua conclusão, procuraremos apenas estabelecer relação conceitual que, aproximando a democracia ao constitucionalismo, seja mais favorável ao conflito e às demais tensões políticas, o que também mostra um certo elo com as perspectivas de Chantal Mouffe e Jacques Rancière.

\section{QUAL DEMOCRACIA?}

Em uma entrevista publicada na coletânea Democracy in What State?, intitulada Democracies Against Democracy, Jacques Rancière sustenta que a aprovação universal da democracia é não só problemática, como também se encontra imersa em equívocos (RANCIÈRE, 2011, p. 76-7). A democracia sobre a qual muitos falam, sobretudo os liberais, é identificada com a organização do poder político, uma forma de Estado que, em sintonia com a economia capitalista, seria capaz de proporcionar um contínuo enriquecimento das nações que adotam os dois em conjunto.

Se durante a Guerra Fria o embate entre democracia e totalitarismo se orientava por uma adesão que não admitia o meio termo, a partir de 1989 a democracia passou a ser vista com outros olhos. Conforme o autor (RANCIÈRE, 2011, p. 76 et seq.), vários dos discursos políticos dominantes nas democracias liberais acabam por conter aspectos francamente antidemocráticos. Um dos exemplos por ele mencionados foi o de um discurso comum nos debates das eleições francesas em 2002: os eleitores eram retratados como irresponsáveis, preocupados apenas com o bem-estar particular e politicamente imaturos no trato das grandes questões coletivas e nacionais (RANCIÈRE, 2011, p. 76-7). Um outro discurso, que é compartilhado por certos políticos e intelectuais, sustenta que, no contexto de um capitalismo dinâmico e democrático, a cidadania acaba cedendo espaço ao consumidor fortemente individualista: seus interesses são voltados predominantemente para a aquisição de bens e 
serviços, deixando os assuntos coletivos aos que por eles nutrem interesse. Sobre este discurso, afirma Rancière em uma entrevista:

Portanto, é preciso opor claramente este exercício da ação cidadã aos discursos moralizantes que se ouvem em quase todos os lugares acerca da responsabilidade dos cidadãos na crise da democracia: estes discursos lamentam todo o desinteresse dos cidadãos pela vida pública, imputando-lhes o rótulo de consumidores individualistas. Estes chamamentos à responsabilidade cidadã tem apenas, de fato, um efeito: culpar os cidadãos para prendê-los ainda mais ao jogo institucional que consiste apenas em selecionar, dentre os membros das classes dirigentes, aqueles por quem os cidadãos preferirão abdicar de seu poder de agir (RANCIĖRE, 2012. Tradução livre).

Ao ressaltar o componente antidemocrático daqueles discursos, Rancière pretende sublinhar, entre outros pontos, as ambiguidades que integram a difusão da democracia. Seu foco não é apenas retratar o déficit de integração e de participação cidadã em meio ao funcionamento das instituições, mas demonstrar como o próprio termo democracia pode servir para justificar e implementar políticas cada vez mais vinculadas aos interesses privados. Neste sentido, por exemplo, partidos políticos, que deveriam defender ideais de segmentos da população, convertem-se em aparatos destinados apenas a conquistar e manter o poder: a representação popular se torna secundária perante os interesses próprios do partido, interesses que podem muito bem estar, de um modo geral, desalinhados com os da população.

Não é difícil transpor esta percepção de população aos atuais debates jurídicos, no Brasil, acerca do ativismo judicial vs. concretização dos direitos fundamentais pela via da adjudicação, que se dá em virtude da ausência ou inépcia do Poder Legislativo federal em cuidar de certas questões. Sem entrar no mérito dos sérios problemas que há no funcionamento institucional dos Poderes Judiciário e Legislativo, como também em torno da devida repartição de competências entre eles, há amplo espaço para se sustentar a ideia de que, sendo os membros do Judiciário normalmente selecionados por concursos públicos, o que se tem é um poder cuja atuação pautada pela técnica não seria, em tese, contaminada pela miopia e ingenuidade da votação popular.

Os dilemas e os impasses trazidos pela democracia podem ser habilidosamente contornados, pela combinação da retórica popular com a administração tecnocrática da política. Em outras palavras, diz-se que a democracia existe e é mantida pelo povo ao mesmo tempo que são tomadas várias providências para mantê-lo afastado dos espaços de tomada de decisão. Ademais, não são poucos que, como F. A. Hayek, concebem a democracia como um mecanismo político cuja utilidade maior é a proteção das liberdades individuais e da estabilidade social (MOUFFE, 2000, p. 3 et seq.). O sistema político, que em tese encontraria 
seus fundamentos de legitimidade nas expectativas e anseios populares, atua e funciona independentemente deles. Ideologias e visões de mundo são substituídas por acordos e alianças estratégicas que perpetuam lideranças e obstruem mudanças significativas.

Uma consequência expressiva dessa situação pode ser - mas não se faz necessária a juridificação da política, ou a transferência das questões e debates de temáticas controvertidas, portanto politicamente carregadas, para um espaço em que a deliberação passa a ser supostamente técnica e despolitizada, como o das cortes constitucionais (MOUFFE, 2000, p. 116). Em solo brasileiro, o tão mencionado protagonismo do Poder Judiciário - e, com ainda mais ênfase, o do Supremo Tribunal Federal - servem para ilustrar esse ponto. A concretização dos preceitos constitucionais, se não é capaz de resolver os entraves do sistema político, ao menos seria apta a minimizar parte dos efeitos de seu funcionamento problemático $^{1}$.

Paralelamente a isso, aposta-se no mercado como o mais eficiente mecanismo para produzir riquezas e reparti-las entre os membros da comunidade. A exaltação do desenvolvimento econômico ora prestigia a flexibilidade da democracia em liberar os impulsos dos consumidores e em desregular os mercados financeiros, ora a condena pelas intervenções no funcionamento do mercado e por medidas tidas como assistencialistas, que desencorajam a competitividade e o crescimento econômico, este parecendo ser o principal parâmetro para auferir o sucesso ou fracasso de um governo democrático.

Rancière observa que, desde as origens na Grécia antiga, as percepções acerca da democracia estão longe de serem positivas, como ocorre com Platão (RANCIÈRE, 2009, p. 35 et seq.). Dando vazão aos desejos mais vulgares das massas impacientes, a democracia traz para perto do exercício do poder expectativas e anseios coletivos que podem desestabilizar e subverter o atual estado das coisas. Não é por menos que Winston Churchill, em uma de suas mais conhecidas citações, teria dito que "a democracia é a pior forma de governo, com exceção de todas as outras já tentadas."

Parcela considerável dos trabalhos teóricos de Rancière consiste em reconsiderar ideias amplamente disseminadas e aceitas, como democracia e igualdade: qualquer constitucionalista e/ou democrata não hesitaria em defender ambas. Mas seria essa uma defesa válida? Por certo, nações não democráticas são vistas como suspeitas pelas que defendem a democracia, mas mesmo entre as nações democráticas proliferam discursos que destacam as

\footnotetext{
${ }^{1} \mathrm{O}$ excelente artigo de Ingeborg Maus, O Judiciário como superego da sociedade: o papel da atividade jurisprudencial na 'sociedade órfã', problematiza muito bem a ascensão social do terceiro poder, com a problemática convergência entre direito e moral, e também com o déficit de participação social. Cf. MAUS, 2002 .
} 
várias implicações prejudiciais à manutenção da ordem e da estabilidade política decorrentes da implementação de um governo democrático.

Para o autor, a luta pelo significado das palavras, pelas direções em que podem ser interpretadas ou concebidos os seus usos, é por si só um exercício político (RANCIÈRE, 2011, p. 78). Os sentidos da democracia não somente se conformam aos usos desta palavra em contextos teóricos e práticos particulares, mas também são torcidos e negociados em meio aos vários embates políticos que enxergam na democracia uma palavra central para a expressão de suas demandas e visões de mundo.

Quando Rancière distingue democracia de uma forma de Estado ou de um ideal político, assim o faz para revelar as bases da própria lógica da política (RANCIÈRE, 2010, p. 30 et seq.). Mas de que modo? Supondo que o poder político fosse a priori concedido aos nobres e aos ricos, não haveria de fato, neste contexto, política: o exercício das prerrogativas dos nobres ou ricos estaria calcado na vontade nua, explícita, sem necessidade de maiores tentativas de legitimação. Ricos e nobres são diferentes e mais fortes; portanto, podem exercer as suas vontades como bem entenderem. As circunstâncias políticas que viabilizam o exercício do ato se devem apenas às condições sociais (riqueza ou poder político) que cada uma daquelas classes já possui.

A democracia, em contrapartida, pressupõe a igualdade (RANCIÈRE, 2010, p. 30-1). $\mathrm{Na}$ medida em que se mostra como governo do povo e para o povo, dois pontos são simultaneamente feitos: 1. A igualdade é inserida na desigualdade; 2 . Cria-se a necessidade de legitimação do poder. Analisemos ambos.

A existência da democracia passa pela constatação das múltiplas desigualdades observadas no espaço social: riqueza, poder, habilidades intelectuais, carisma, status etc. Desigualdades fazem com que parcelas e segmentos da sociedade sejam situados simbolicamente - e por vezes fisicamente - fora da sociedade. Não apenas estão distantes dos principais centros de tomada de decisão política, como também não são considerados por ele: são os que, por não possuírem quaisquer títulos ou propriedades, não estão, a priori, propensos ao exercício do poder. Uma vez que atribui pesos diferentes para cada um, valendo-se de critérios de importância arbitrariamente fixados (riqueza, status, habilidades intelectuais...), conceberemos essa forma de contagem como geométrica (RANCIÈRE, 1999, p. 30-1).

As desigualdades também limitam as possibilidades de transformações das circunstâncias dos menos favorecidos, uma vez que podem - e normalmente irão - distinguir o que é próprio, em termos de participação e reinvindicação, daquilo que seria impróprio. A 
mudança, quando existe, é controlada para que não prejudique ou desestabilize a contagem geométrica que lhe tornou, em primeiro lugar, possível.

Quando os segmentos desfavorecidos exigem que sejam contados exatamente como os mais favorecidos, anseiam que as suas necessidades e carências sejam também consideradas. Esse movimento coloca em questão a ordem dominante a partir da contagem que recai sobre os membros da sociedade. Ao menos em tese, a contagem democrática nivela a todos no conceito de povo, que transcende as múltiplas formas de classe: o privilégio da democracia, por assim dizer, é a anulação de qualquer privilégio prévio, intrínseco ou essencial, para que se possa governar. Os privilégios para governar, por exemplo, são separados de qualquer relação com uma ordem social, natural ou mesmo convencional: a rigor, todos têm esse privilégio. É essa abertura, no sentido de um privilégio que a todos se estende - e, portanto, em um sentido lógico, não se trata mais de privilégio - que o filósofo deseja explorar em sua discussão acerca da democracia:

\begin{abstract}
É simplesmente a dissolução de qualquer padrão pelo qual a natureza possa proporcionar um direito a um artifício comunitário mediante relações de autoridade que estruturam o corpo social. $\mathrm{O}$ escândalo reside no desacoplamento entre privilégios para governar e qualquer forma de analogia para com as relações de ordem social, e também com qualquer analogia com convenções humanas e com a ordem da natureza. É o escândalo de uma superioridade baseada na própria ausência de qualquer forma de superioridade (RANCIÈRE, 2009, p. 41. Tradução livre).
\end{abstract}

Essa contagem, no entanto, existe somente enquanto contraposta a um outro tipo de contagem: uma que considera cada um diferentemente, com pesos diversos (TANKE, 2011, p. 48 et seq.). Alguns são mais importantes e esclarecidos do que outros; devem, portanto, encarregar-se da política. Como ocorrera em nosso exemplo dos ricos e nobres, o exercício do poder, aqui, não necessita ser legitimado: a desigualdade que torna viável o seu exercício é a mesma que também o justifica.

Democracia, portanto, tem um significado muito diferente, para Rancière, em relação àquele que é praticamente um consenso atual entre teóricos da política e juristas. Identificar a democracia com uma forma de Estado, por exemplo, implica ignorar o funcionamento de uma lógica política que atualiza e reforça a igualdade como pressuposto, não como um fim ou meta presente nas várias constituições, mas que depende da atuação dos Três Poderes para ser implementada (TANKE, 2011, p. 36). Deixada de lado aquela lógica, a democracia se torna domesticada, pacificada, alvo de reformas incipientes: o poder do povo vira um slogan vazio, retórico, utilizado por políticos das mais diversas (e opostas entre si) inclinações.

Ao questionar o arranjo da ordem social, ao demandarem que sejam tratados como iguais, os excluídos buscam expor não apenas a circunstância desigual em que se encontram, Revista da Faculdade de Direito - UFPR, Curitiba, vol. 59, n. 3, p. 167-196, 2014. 
mas também querem apontar para uma fragilidade na legitimação do exercício do poder político. Em outras palavras, querem discutir os pesos e os cálculos responsáveis por deixálos à deriva das decisões políticas.

Em síntese, o autor confronta o conceito usual de democracia principalmente porque a compreende como uma forma de Estado. A concepção de democracia que ele oferece, em contrapartida, acaba sendo mais aberta e complexa do que a confrontada. Ela é concebida como um poder - ou mesmo força - popular em constante conflito com o Estado:

Ela é, primeiramente, a realidade de um poder do povo, que não pode jamais
coincidir com uma forma de Estado. Sempre haverá tensão entre a democracia,
como exercício de um poder compartilhado de pensar e agir, e o Estado, desejoso de
se apropriar desse poder. Evidentemente, os Estados justificam essa apropriação
argumentando sobre a complexidade dos problemas, a necessidade de se pensar a
longo prazo, dentre outras justificativas. Mas a verdade é que os políticos estão
muito mais presos ao presente. Recuperar os valores da democracia é, em primeiro
lugar, reafirmar a existência de uma capacidade de julgar e decidir, que a todos se
estende, frente a essa monopolização (RANCIĖRE, 2012. Tradução livre).

Essa tensão entre democracia e Estado é central para a compreensão que o autor tem da política, como veremos na seção seguinte, como também para a sua revitalização do conceito. Revitalização na medida em que concebe a democracia como uma força que continuamente desestabiliza e põe em xeque o status quo. Isso é um ponto significativo porque, ao conduzir a sua reflexão por esse percurso, o autor busca se desvencilhar das várias teorias liberais normativamente comprometidas com a democracia (TANKE, 2011, p. 44 et seq.).

Nesta primeira seção verificamos como desacoplar a democracia do Estado ou dos limites institucionais do poder. Essa preocupação é também compartilhada no artigo de Vera Karam, em especial na ênfase que dá ao poder constituinte e na tentativa que a autora faz de impedir que a reflexão acerca da Constituição esteja limitada pelo poder constituído e/ou pelas constituições positivas, empíricas. A preocupação dela, como a nossa, no que concerne ao exposto nesta primeira seção, consiste em reafirmar a potencialidade das mobilizações e das interações populares como força capaz de modificar a dinâmica das instituições que, muitas vezes, mostram-se opressivas e excludentes.

A tensão entre o poder da democracia e a forma de Estado que tenta absorver e assimilar essa potência é muito bem aprofundada e discutida por Rancière via introdução de um importante binômio: polícia e política. Este será o centro da próxima seção. 


\section{POLÍCIA OU POLÍTICA? - DEMOCRACIA ALÉM DO CONSENSO}

Rancière entende por polícia algo relativamente próximo do que concebemos como política: o exercício do poder, legítimo ou mesmo ilegítimo, sobre um coletivo (RANCIÈRE, 1999, p. 28 et seq.). Vários atos e determinações são compreendidos por esse exercício. Dentre outros, decisões meramente administrativas e a produção de leis. Os detalhes que permeiam o exercício do poder importam menos do que o caráter técnico que o acompanha e a busca pela estabilização das relações sociais. A polícia impõe e reforça uma configuração social específica que delimita os contornos da comunidade: o problema é que a cidadania acaba se convertendo em um problema administrativo.

A polícia concebe as relações sociais a partir de hierarquias de papéis e funções, fixando o que pode ser discutido, problematizado, e o que não pode. Ela distribui os corpos dos cidadãos, inclusive fixando os limites da participação política e do que eles, os cidadãos, podem fazer para transformar as suas circunstâncias. Por exemplo, podem barganhar com o empregador os seus salários, desde que seguindo os procedimentos - jurídicos ou não - para o tratamento desta questão; a greve, que onera o empregador, é firmemente desaconselhada quando confronta os procedimentos estabelecidos.

Procedendo deste modo, a polícia fecha inúmeras possibilidades futuras em prol daquelas que já se encontram atualizadas no presente. Este, aliás, surge como naturalizado, autoevidente: contestá-lo implicaria, ao menos em tese, realizar o tipo de reflexão utópica e pouco produtiva para resolver problemas concretos apresentados pela sociedade (TANKE, 2011 , p. 47 et seq.). A polícia, pois, concebe a ordem social como uma totalidade uniforme e não cindida por conflitos entre classes ou segmentos: todos, em princípio, encontram-se sob a sua administração.

Um dos pressupostos básicos da totalidade é o de que não existem elementos excluídos: todos são parte da sociedade (RANCIÈRE, 1999, p. 123 et seq.). Imigrantes e desempregados, por exemplo, são concebidos como partes dessa totalidade, embora nela não tomem parte, ou seja, suas opiniões, necessidades e crenças não são tidas como relevantes no esquema hierárquico montado pela polícia (TANKE, 2011, p. 43 et seq.). Podem até ser considerados cidadãos, mas o exercício de suas prerrogativas mostra-se limitado ao ponto de a cidadania, para estes grupos, ser uma promessa vazia, um lembrete de que, na comunidade em que se inserem, eles dificilmente têm como vir a ser parte.

A manutenção da ordem, no entanto, depende de uma contagem geométrica, logo desigual, mas que tem como sua base a igualdade. A organização hierárquica das partes se 
mantém por meio de uma fixação de critérios com os quais se pode mensurar a importância da função e o papel de cada parte na totalidade - daí falar-se em geometria. Entretanto, a opção por determinados critérios implica também a elaboração de justificativas, utilizadas para tornar essa opção aceitável aos segmentos não beneficiados por ela (MAY, 2008, p. 107 et seq.).

Embora as justificativas, ao buscarem se comunicar com os segmentos desprivilegiados, almejem tornar aceitável a desigualdade, os privilegiados mostram um espaço comum e igualitário entre si e os desprivilegiados: estes entendem e assimilam a linguagem dos privilegiados, mostrando-se, aqui, iguais a eles. A desigualdade inscrita na estrutura da ordem social tem como fundamento a igualdade pré-existente revelada na comunicação entre segmentos díspares.

A política aparece em momentos excepcionais, quando o coletivo fragilizado (os que não tomam parte) confronta o arcabouço administrativo - o poder instituído, assim podemos dizer - da sociedade (RANCIÈRE, 1999, p. 29 et seq., p. 123). A íntima relação entre a política e a democracia se torna visível: o confronto com o status quo ocorre em meio a uma circunstância de desigualdade a que se busca modificar mediante um apelo à igualdade (RANCIÈRE, 2011, p. 79). O escândalo da democracia, como observamos, tem início não quando os escravos manifestam revolta com o tratamento que recebem, mas quando clamam pela igualdade, no contexto de uma organização social fundada na própria desigualdade.

Como o sentido das palavras é continuamente negociado pelas múltiplas forças políticas que pretendem impor aquilo que reflete os seus interesses e necessidades, o termo democracia, na contemporaneidade, abrange os significados mais diversos e contraditórios. Se o consenso sobre a importância e as múltiplas vantagens de se adotar a democracia mostrase preponderante, isso também significa que as propriedades e características que tornavam esse conceito contestável passam agora a permanecer latentes (RANCIÈRE, 2009, p. 3).

A ambiguidade deste conceito muito interessa a Jacques Rancière. Por um lado, a palavra democracia integra o discurso de ordem das superpotências econômicas perante os países que ainda não a adotaram: sem a democracia, supõe-se que o crescimento e a estabilidade econômica estarão em permanente ameaça. Por outro lado, ela traz consigo transformações, como as proporcionadas pelas ações afirmativas e os demais direitos civis e sociais das várias minorias políticas, criando tensão entre essas transformações e os interesses e necessidades do status quo. Essa mesma ambiguidade vai se reproduzir nos espaços nacionais e internacionais. 
No âmbito internacional, a democracia converte-se em produto de exportação privilegiado, visando à expansão do capitalismo global, ao mesmo tempo que, no nacional, ela é rechaçada por viabilizar transformações sociais que modificam radicalmente as relações que compõem a comunidade. Vejamos como essa dualidade é captada pelo autor:

De fato, os mesmos críticos que ininterruptamente denunciam a América democrática por nos ter proporcionado todos os males associados ao respeito pelas diferenças, direitos de minorias e ações afirmativas, que por sua vez fragilizam a universalidade da república francesa, são também os primeiros a aplaudir quando a mesma América busca espalhar a democracia ao redor do mundo por meio da força armada (RANCIÈRE, 2009, p. 3. Tradução livre).

Essa ambiguidade nos mostra o porquê da cautela quanto à adesão e à difusão da democracia, sobretudo no consenso em torno de sua defesa. O conceito de consenso, aliás, é um dos pontos em que a reflexão política de Rancière se mostra um tanto quanto distinta no panorama da filosofia política contemporânea, especialmente em relação à liberal ${ }^{2}$. O autor entende que a ideia de consenso está atrelada à separação entre próprio e impróprio, criando uma distribuição hierárquica de posições no espaço social que, por sua vez, define o lugar de cada um. O discurso de cada um é determinado em conformidade com a sua ocupação no espaço social (CORCORAN, 2010, p. 2). O que predomina no consenso é a identidade:

Trata-se de casar a poiesis, ou modo de criação, com a aisthesis, ou horizonte de afetos. A essência do consenso, portanto, é a suposição de uma identidade entre um sentido e outro, entre o fato e a sua interpretação, entre o discurso e o seu relato, entre o status factual e os direitos assegurados etc. (CORCORAN, 2010, p. 2. Tradução livre).

O consenso, a partir da configuração afetiva em que ele se insere, limita o horizonte: a criação só se faz possível dentro dos limites e confinamentos impostos pelo presente. É lugar comum, hoje, afirmar que transformações sociais precisam respeitar o capitalismo, a democracia e os direitos humanos. São três elementos que integram o nosso presente e que influenciam profundamente a visão que temos das relações sociais, mas que também determinam o que podemos esperar em termos de transformações futuras. Neste tipo de lógica, o problema não são as transformações e reinvindicações, mas sim como administrálas. Daí a ênfase na identidade, na delimitação de posições e funções que cada um deve ocupar. A preocupação principal é com o controle.

\footnotetext{
${ }^{2}$ Nossa concepção deste conceito segue a de Chantal Mouffe em On the Political: “A compreensão tipicamente liberal do pluralismo é a de que vivemos em um mundo em que existem inúmeras perspectivas e valores, e que por conta de limitações empíricas, jamais seremos capazes de adotar todos eles, mas, juntos, eles constituem um conjunto harmônico e não-conflituoso. É por isso que este tipo de liberalismo precisa negar o político em sua dimensão antagônica" (MOUFFE, 2005, p. 10. Tradução livre). 
O dissenso opera de forma bastante diversa: o seu foco reside na impropriedade e no espaço entre a poiesis e a aisthesis, proporcionando um rompimento com a polícia e, assim, o aparecimento da política (HEMEL, 2008, p. 21; MALIK; PHILLIPS, 2011, p. 112-3). Esta é concebida como carente de essência, uma vez que o modo de criação separa-se do atual horizonte sensível. Sob a lógica do dissenso, a política é um processo que impede a colocação de qualquer fundamento que venha a introduzir uma positividade de uma esfera: ela borra e desestabiliza fronteiras e determinações firmadas. Se o consenso remete a uma clara delimitação entre o próprio e o impróprio a cada domínio específico (o sistema político, o social, a vida particular), sob a lógica do dissenso a política fará o contrário, ao expor a instabilidade dessas fronteiras:

A política, então, ao invés de consistir em uma atividade que tem como fundamento a sua separação do domínio do social, é uma atividade que consiste apenas em borrar as fronteiras entre o que é considerado político e o que é considerado próprio para o domínio do social e da vida privada (CORCORAN, 2010, p. 3. Tradução livre).

O que é problemático na lógica do consenso, principalmente quando concebida a partir das democracias contemporâneas, é a concepção de uma ordem social comum e avessa aos conflitos. As bases da democracia consensual remetem à ideia de unidade e de estabilidade do corpo social, o que se traduz em uma acentuada preocupação com o controle. Controlar indivíduos, seja pela incomensurável diversidade que apresentam, ou também por sua quantidade, é tarefa por certo inviável, mas, quando eles são subsumidos a uma totalidade homogênea e delimitada - a população -, o controle se torna real. Indivíduos possuem necessidades, desejos e anseios os mais variados e incompatíveis entre si; à população, enquanto entidade abstrata, pode ser atribuído um conjunto de necessidades e desejos coerentes e compatíveis entre si.

Percebe-se que, diferentemente dos indivíduos, a população não expõe por si só os seus desejos e necessidades: estes são extraídos por meio das investigações e pesquisas estatísticas realizadas por experts e administradores. A satisfação de necessidades precisa ser calculada a partir das possibilidades que emergem de uma análise objetiva da situação.

Um bom exemplo utilizado por Steven Corcoran consiste na situação do trabalhador, antes um ator político que lutava pela igualdade, e agora um sujeito que possui direitos em conformidade com a função que desempenha, direitos que, cada vez mais, são reduzidos para viabilizar a proteção de empregos no mercado de trabalho: quanto maiores os custos trabalhistas e mais cara uma mão de obra, menor será a sua atratividade ao empregador. A proteção do emprego, no entanto, tem seus limites na objetividade da situação: todos os que 
se situam fora da identidade do trabalhador cujo trabalho deva ser preservado, como os imigrantes ou desempregados, são deixados de lado (CORCORAN, 2010, p. 5).

A desestabilização provocada pela política nos chama atenção para a exclusão e - o que é ainda mais importante - o silêncio que paira sobre os que não são parte: quando conseguem falar, o conteúdo daquilo que falam é considerado puro ruído, destituído de qualquer significação; sons que expressam apenas alienação e ignorância. $O$ discurso democrático calcado na totalidade da população é prontamente abandonado quando aqueles que não são parte decidem expor suas preferências eleitorais: uma democracia tida como séria, argumenta-se com certa frequência, não poderia ficar à mercê desses segmentos, ou mesmo ser influenciada por eles.

Chantal Mouffe é bastante incisiva quanto ao papel fundamental do conflito nas democracias contemporâneas, sendo este um ponto recorrente e central na sua abordagem da política. Uma das promessas da democracia liberal consiste em ressaltar o enfraquecimento dos vínculos que possuem identidades coletivas, construídos pelos indivíduos: esquerda e direita, capitalistas ou socialistas, são, em princípio, terminologias que perdem a sua força e estabilidade em um mundo cada vez mais marcado pela complexidade e liberdade (MOUFFE, 2005, p. 71-2; MOUFFE, 1993, p. 48 et seq.).

Nesta forma de utopia pós-política, cada um se torna livre para seguir com o estilo de vida ou visão de mundo que mais achar frutífero(a). Essa concepção restrita de cidadania, que vislumbra no indivíduo e na defesa das suas prerrogativas individuais o eixo central de sua preocupação, acaba por produzir déficits intensos de legitimidade no que concerne às instituições políticas. Longe de se construir uma sociedade sem conflito, o que ocorre é uma forma de sufocamento das relações de antagonismo. Em um dado momento, o antagonismo retorna à arena política, mas agora sob uma forma destrutiva, nacionalista ou populista de extrema direita.

Eu argumentei que, como consequência da indefinição das fronteiras entre esquerda e direita e da ausência de um debate agonístico entre partidos democráticos, no sentido de um confronto entre diferentes projetos políticos, os eleitores não tiveram à sua escolha uma gama diferenciada de identidades políticas democráticas. Isso criou um vazio a ser provavelmente ocupado por outras formas de identificação, que podem se tornar problemáticas para o funcionamento do sistema democrático. Eu sustentei que, apesar do anúncio do desaparecimento das identidades coletivas e da vitória do individualismo, a dimensão coletiva não poderia ser eliminada da política (MOUFFE, 2005, p. 69-70. Tradução livre) $)^{3}$.

\footnotetext{
${ }^{3}$ As bases desse argumento remontam à psicanálise de Freud e Lacan, considerando-se também as leituras de Slavoj Zizek e Yannis Stravrakakis, o que em muito ultrapassa a pretensão deste artigo. Para um maior aprofundamento sobre este ponto, cf. MOUFFE, 2005, p. 25-9.
} 
Ainda que um tanto quanto diferente da abordagem apresentada por Jacques Rancière, o posicionamento de Mouffe apresenta, em relação a ela, certas aproximações (MOUFFE, 2005, p. 29). No caso do autor francês, a lógica do consenso remete o social a uma totalidade da qual todos são parte, embora, como já o dissemos, dela muitos não tomem parte: o conflito que poderia ser desenvolvido entre projetos políticos concorrentes é subsumido em propostas políticas de cunho administrativo e operacional. Todo consenso, lembra-nos Mouffe, seguindo os passos de Carl Schmitt, é baseado em atos de exclusão, por mais discretos que sejam (MOUFFE, 2005, p. 11).

Um dos efeitos colaterais desse ponto - e que recebe bastante atenção da autora consiste na ascensão cada vez mais incisiva dos partidos populistas de extrema direita nos países da União Europeia: trata-se de uma das formas de identificação que introduzem entraves significativos para o funcionamento da democracia. Isso porque os partidos populistas, guiados por nacionalismos cegos, não buscam lidar com um adversário político que, embora sustente projetos políticos opostos, deve ser reconhecido e respeitado, e sim com inimigos, entes que devem ser extirpados da comunidade social e política (MOUFFE, 2005, p. 66 et seq.). A distinção entre inimigo e adversário se torna crucial para o surgimento e a manutenção de uma ordem democrática e pluralista, considerando que a dinâmica do conflito não tem como ser erradicada da vivência política:

\footnotetext{
Uma vez que aceitemos a necessidade do político e a impossibilidade de um mundo sem antagonismo, será necessário vislumbrar como é possível, nessas condições, criar ou manter uma ordem democrática. Essa ordem é baseada na distinção entre 'inimigo' e 'adversário'. Ela requer que, no contexto da comunidade política, o oponente não seja considerado um inimigo a ser destruído, mas um adversário cuja existência é legítima e precisa ser tolerada. Nós lutaremos contra as suas ideias, mas não colocaremos em questão o seu direito de defendê-las (MOUFFE, 1993, p.4. Tradução livre).
}

A imagem coletiva dos imigrantes, por exemplo, pode ser discursivamente reconstruída, pelos propagandistas daqueles partidos, como a de um grupo cuja meta principal é se apropriar dos empregos e dos recursos financeiros das nações em que se instalam sem oferecer algo em troca: não aprendem o idioma local, não assimilam as tradições e valores e, em muitos casos, isolam-se em ghettos étnicos, reduzindo o quanto possível a interação com os próprios cidadãos. Como, então, concebê-los como uma presença política e social benigna ao desenvolvimento da comunidade?

O problema não reside na tensão política introduzida pelo partido extremista, mas na estrutura e no fim a que essa tensão acaba sendo direcionada. A dificuldade da democracia, para Mouffe, consiste em preservar - ou mesmo balancear - a associação política, isto é, o 
respeito entre os diversos grupos políticos, com o conflito que advém da incompatibilidade entre os projetos políticos sustentados por cada um deles: o consenso deve vir acompanhado pelo dissenso (MOUFFE, 2000, p. 113 et seq.; MOUFFE, 1993, p. 146 et seq.). Essa forma de balanceamento é bem retratada no conceito de agonismo empregado por Mouffe (MOUFFE, 2005 , p. 20 et seq.).

O agonismo concebe o conflito e os embates políticos de maneira diversa do antagonismo: no primeiro, reconhece-se que as alternativas políticas a uma determinada situação ou problema não podem ser conciliadas, mas se respeita a posição adversária. No segundo caso, referente ao antagonismo, o conflito é orientado para a exclusão e/ou eliminação do outro, relação que pode ser estruturada e representada no par amigo/inimigo ou nós/eles. É este segundo caso que reflete as propostas políticas, bastante prejudiciais ao funcionamento da democracia, dos partidos populistas de extrema direita, conforme a autora (MOUFFE, 2005, p. 69-72).

Este balanceamento pode ser traduzido em respeito mútuo e em um conjunto de regras e preceitos que tornam viável a própria divergência política. A ascensão dos partidos de extrema direita, então, pode ser ao menos ponderada, quando observamos que, em várias democracias liberais contemporâneas, não há sequer opções partidárias cujas orientações ideológicas se mostrem distintas, tampouco - talvez pela própria ausência de diversidade - o conflito. Considerável parte das divergências políticas acaba recaindo sobre questões técnicas que deixam de lado uma visão mais global acerca das transformações sociais que cada grupo pretende impulsionar.

O importante a ser considerado neste capítulo é que a política é algo mais do que a administração das necessidades sociais, da mesma forma que a democracia não se confunde com uma forma de Estado, como observamos na primeira seção. Considerando que a política não é administração, enfatizar o espaço de conflito adquire importância não apenas como forma de impulsionar transformações sociais significativas, mas, também, para revelar o caráter profundamente problemático da política: as constantes menções à desestabilização tiveram em mente o destaque desse ponto.

Acrescentamos algumas considerações oriundas dos trabalhos de Chantal Mouffe com o intuito de ressaltar como o conflito pode ser concebido de modo a aprofundar e resguardar uma dinâmica política produtiva nas democracias liberais ocidentais. Os conceitos de agonismo e antagonismo serviram para embasar este ponto. Por meio do conceito de agonismo, o conflito pode ser pensado como algo que permite o embate entre projetos 
políticos contraditórios, ao mesmo tempo que as partes envolvidas se enfrentam como adversárias, não como inimigas.

No artigo de Vera Karam (CHUEIRI, 2013, p. 32-4), a tensão entre constitucionalismo e democracia é organizada de modo a permitir, simultaneamente, impulsos que buscam transformações sociais profundas por meio do exercício da cidadania e a preservação do aparato institucional, de modo a assegurar as conquistas antigas e as recentes. A Constituição pode ser compreendida como um dos limites que faz a distinção entre o agonismo e o antagonismo, entre o conflito que favorece a dinâmica democrática e aquele que a rejeita.

Uma vez apresentadas, conforme a proposta deste artigo, as posições de Rancière e Mouffe, cabe agora apontar como ambas podem contribuir para uma leitura da proposta de Vera Karam. Alguns paralelos já foram observados, é certo, mas foram tênues e tinham, como pretensão, mais o desenvolvimento da exposição do pensamento dos autores do que o diálogo, propriamente dito, com a ideia de Constituição radical e também com o constitucionalismo. A próxima seção será dedicada a esta tarefa.

\section{O REGIME ESTÉTICO DO CONSTITUCIONALISMO}

Existem ao menos dois pontos decisivos, em nossa breve exposição do pensamento de Jacques Rancière, que se mostram frutíferos para uma articulação com as ideias propostas pela professora Vera Karam em torno da Constituição radical. O primeiro lida com as relações de inclusão/exclusão (ou próprio/impróprio), indispensáveis ao cálculo geométrico sustentado pela polícia, enquanto o segundo se refere à desestabilização da ordem social pela política. Juntos, as suas subseções pretendem estabelecer paralelos diretos com os conceitos empregados por Vera Karam no tocante à Constituição radical.

\subsection{AS RELAÇÕES DE INCLUSÃO/EXCLUSÃO NO CONTEXTO CONSTITUCIONAL}

Referente ao primeiro ponto, Vera Karam ressalta, em vários trechos do seu artigo, uma separação, ainda que relativa, entre a ideia de Constituição e a sua expressão concreta, factual, que aqui chamaremos de presente: “... não exatamente da norma promulgada em 1988, não do texto que a revela, mas também isso, na medida em que a Constituição não se deixa reduzir ao constituído" (CHUEIRI, 2013, p. 26). Se a atualidade da Constituição permite a operacionalidade jurídica dos direitos e garantias fundamentais, que são também 
conquistas políticas significativas, em contrapartida não é adequado conceber a Constituição como capaz de controlar - e, por que não, resolver? - as tensões presentes nos embates políticos. Uma visão como essa coloca a Constituição como superior àqueles embates. Não só sustentamos que se trata de um posicionamento teórico ingênuo, como também defende Vera Karam, mas também que se trata de mais uma tentativa inadequada de juridificar a política.

Com Rancière, nós observamos como a polícia implanta um regime estético sobre o presente, delimitando o visível e o invisível, o próprio e o impróprio, o que é significativo e aquilo que deve ser ignorado. Esse regime, que chamaremos de estético, também vai aparecer quando a Constituição é concebida somente em sua atualidade/efetividade, e não, também, como fonte de possibilidades.

A anulação da tensão entre o presente e o futuro, entre o atual e o possível, tem algumas implicações produtivas. Uma delas, a juridificação da política, termina concebendo os embates e conflitos como atividades que reiteram, portanto não criam nem transformam, os conteúdos normativos da Constituição. Como esta seria, ao menos em tese, capaz de absorver as tensões políticas propondo respostas jurídicas, que se presumem despolitizadas, os conflitos podem ser dissolvidos na prática de adjudicação do Poder Judiciário. Tal concepção deixa de lado a indispensável atuação dos vários movimentos sociais que há décadas têm lutado pela aquisição e efetivação de direitos suscetíveis de proporcionar transformações significativas às circunstâncias dos seus integrantes.

Esse é um ponto que pode ser beneficiado pela distinção que Rancière estabelece entre polícia e política no contexto democrático. O separados mas iguais não deve ser concebido apenas como um slogan voltado para a difusão de um projeto social preconceituoso e racista, mas também como a inclusão sistemática de formas de exclusão oficializadas. Em outras palavras, os negros libertos não estavam situados fora da sociedade, como entidades externas e desconhecidas: eram cidadãos americanos livres, mas, também por causa dessa condição, experimentavam a exclusão em uma sociedade que não os considerava como parte legítima. Sendo negros, descendentes de escravos, representavam uma minoria social que confrontava o imaginário sociocultural dos WASP (White, Anglo-Saxon and Protestant Branco, Anglo-Saxão e Protestante).

A cor da pele e a linhagem histórica atuavam como critérios que opunham o discurso legítimo (o dos brancos) ao mero barulho irracional e supersticioso dos negros e dos nativos. Nesta sociedade, em que, em princípio, todos são concebidos como partes, apenas alguns, de fato, podem sequer pensar em tomar parte. Desnecessário dizer que as marcas deixadas por 
uma organização social como essa não podem ser superadas por qualquer lei ou decisão judicial, ainda que ambas sejam importantes para esse processo.

O trabalho paciente e contínuo dos movimentos sociais sublinha o hiato entre as configurações atuais da sociedade e as possibilidades de transformação que, sendo implícitas, podem ser trazidas à tona. Durante muitos anos, indígenas, negros e homossexuais, entre outros, não integravam o nós que utilizamos para mencionar os cidadãos de nossa comunidade. Vivendo entre nós, permaneciam excluídos dos laços de solidariedade e aproximação que configuravam a participação na esfera civil.

Retomamos o exemplo do separados mas iguais da sociedade norte-americana, em que a exclusão era sistematicamente reproduzida e legitimada pelo aparato institucional. Ali, uma possível, embora improvável, concretização dos direitos, dificilmente viabilizaria uma transformação mais acentuada na condição daquele coletivo, uma vez que a hegemonia das forças políticas já havia naturalizado o papel subserviente a ser ocupado por aquelas pessoas. É inviável que o sujeito de direito consiga desfrutar dos seus direitos se o seu status de sujeito é, de antemão, sistematicamente desrespeitado.

Ao contrário dos vários países conhecidos pelo amplo desenvolvimento do seu constitucionalismo, a sociedade brasileira ainda mantém um quadro generalizado de exclusão social e econômica. Diferentemente das desigualdades de renda ou de oportunidades, presentes em maior ou menor escala em muitos países economicamente desenvolvidos, no Brasil há uma significativa parcela da população que vive o seu cotidiano às margens dos direitos fundamentais a ela atribuídos, expressamente, pela Constituição brasileira. Para muitos brasileiros, a cidadania representa escassez de direitos em meio à abundância de deveres.

Seguindo o percurso de Jacques Derrida no tocante à democracia por-vir, Vera Karam (CHUEIRI, 2013, p. 27) ressalta o caráter indeterminado da Constituição radical, que possui um apelo à temporalidade: um futuro que escapa das determinações e construções teóricas do presente. Ressaltemos que a ênfase que damos ao presente não tem como intuito a projeção da Constituição radical em uma ordem transcendente, criando um fosso entre presente e futuro. Antes - e esse é um ponto relevante tanto para o artigo de Vera Karam (CHUEIRI, 2013, p. 27-8) como para o nosso -, é a concepção de um futuro indeterminado e aberto que aponta a instabilidade da presente ordem social ao mesmo tempo que revela possibilidades de transformação que ainda não foram sequer consideradas. Dito de outro modo, a ideia de Constituição proporciona um excesso, surplus, que escapa às suas múltiplas 
manifestações empíricas - e, neste ponto, a influência de Jacques Derrida é muito clara (MOUFFE, 2000, p. 12 et seq.).

Essa preocupação com as possibilidades futuras é uma constante também no trabalho de Jacques Rancière (BIEST; BINGHAM; RANCIÈRE, 2010, p. 74 et seq.). A tarefa da polícia obviamente não é a inviabilização das transformações ou mudanças sociais, mas o controle sobre as possibilidades que podem ser concebidas e atualizadas. Ao delimitar e organizar o próprio e o impróprio, a polícia impõe rotas específicas de concessão, ao mesmo tempo que exclui outras. Logo, ela não deve ser associada de imediato a formas visíveis de repressão, mas à limitação e controle de mudanças e perspectivas (RANCIÈRE, 2009, p. 28 et seq.).

O que é determinante, neste primeiro ponto, é a atenção às relações de inclusão/exclusão associadas ao regime estético. A inclusão é, afinal, um dos principais valores da democracia, se não é, mesmo, o seu principal valor. Pensar este ponto implica também colocar em perspectiva uma das ideias centrais do artigo de Vera Karam e também do nosso: a abertura da Constituição a partir de uma concepção de futuro que é não-redutível à dimensão normativa presente em seu texto. Esse é um ponto que traz implicações complexas e, em certo sentido, aporéticas.

Por um lado, a normatividade do constitucionalismo termina por se mostrar restritiva e retrospectiva, subordinando uma compreensão do futuro aos compromissos firmados no passado e no presente. O problema nós já apontamos: a limitação da soberania popular pelo constitucionalismo praticamente assimila, uma vez realizado o ato fundante da Constituição, o poder constituinte ao poder constituído. O poder constituinte acaba sendo concebido, após a implementação da Constituição, como construção metafísica e juridicamente irrelevante: uma ficção empregada para explicar a origem e a legitimidade democrática da Constituição, mas que, em termos jurídicos, não se presta à operacionalidade.

Em contrapartida, um rompimento com as amarras do constitucionalismo pode transformar um regime democrático em um espaço de barbárie: o abuso de poder pela maioria não é aqui possível, porque nem sequer existem limites normativos ao seu exercício. Suficiente dizer que em um regime como esse há espaço para a proliferação das mais variadas formas de intolerância e autoritarismos.

Podemos sintetizar o ponto principal desta seção da seguinte forma: é necessário compatibilizar mecanismos jurídicos de defesa dos direitos das minorias sem esquecer que esses mesmos mecanismos são moldados pelas relações agonísticas - mas também as moldam - no espaço social. Em outras palavras, a Constituição precisa impedir e bloquear mudanças 
que se pautam por rumos indesejáveis para a sociedade, ao mesmo tempo que os próprios critérios que podemos utilizar para determinar o que seria desejável/indesejável não podem, por si só, serem determinados juridicamente (CHUEIRI, 2013, p. 33).

Cria-se com isso uma relação que só pode ser caracterizada como circular: a Constituição intervém e limita transformações sociais que, por seu turno, podem transformar a Constituição e/ou a interpretação que temos dela. Como não é possível conceber uma Constituição desvinculada do contexto sociopolítico que ela mesma tende a estruturar normativamente, também não é possível desconsiderar as consequências das relações de inclusão/exclusão para a compreensão e concretização do texto constitucional.

A mencionada circularidade se traduz em uma relação do intérprete com o passado marcada por uma apropriação contínua, porém criativa (GADAMER, 2005, p. 356). Pode-se dizer que a relação é simultaneamente retrospectiva e prospectiva: retrospectiva, uma vez que a tradição é indissociável da compreensão do intérprete, ou seja, não pode ser abstraída; prospectiva, porque a tradição envolve também aquilo que o intérprete, em seu horizonte, acaba por acrescentar ao encontro. Representa o que Hans-Georg Gadamer concebe como fusão de horizonte. Todo passado, portanto, é sempre uma possibilidade desvelada no presente $^{4}$.

A relação entre poder constituinte e poder constituído pode encontrar, nessa reflexão hermenêutica, um paralelo interessante: compreende-se o poder constituinte como a tradição à qual o poder constituído se encontra vinculado em meio a uma relação dinâmica de interpretação. Trata-se de uma relação ontológica: toda interpretação da Constituição remete, embora, na maior parte das vezes, de maneira muito implícita, à experiência fundadora do poder constituinte. Não se trata de uma consideração metodológica ou que corresponda a uma ação ou omissão do intérprete; antes, diz respeito à sua condição.

Um conceito constitucional que traduz adequadamente a imposição de limites às transformações do poder constituído é o da cláusula pétrea. Observemos que, referentes aos direitos e garantias individuais (BRASIL, Art. $60, \S 4^{\circ}$, IV), a atuação dos movimentos sociais proporcionou - e ainda proporciona - novos modos de se compreender direitos e garantias responsáveis por produzir transformações significadas na sociedade civil - o sistema de cotas e o casamento entre pessoas do mesmo sexo são dois exemplos recentes e corriqueiros. Ainda

\footnotetext{
${ }^{4} \mathrm{O}$ aprofundamento dessa investigação hermenêutica é algo que ultrapassa as pretensões deste artigo. Entretanto, por ser um ponto muito fecundo, recomendamos uma leitura da seção 2 da segunda parte de Verdade e Método de Gadamer, em especial a 2.3 (GADAMER, 2005, p. 354-493). Seguindo a exposição de Christopher Watkin (2009, p. 117 et seq.), acreditamos que essa investigação pode ser bastante enriquecida com uma incursão no pensamento de Paul Ricoeur, em especial no que se refere à justiça e à interpretação. Revista da Faculdade de Direito - UFPR, Curitiba, vol. 59, n. 3, p. 167-196, 2014.
} 
que o Art. 226, nos parágrafos $\S 3^{\circ}$ e $\S 4^{\circ}$, da CF/88 (BRASIL, 1988) deixe explícito que o casamento está firmemente atrelado à união heterossexual, novas concepções em torno da hermenêutica jurídica constitucional e da relevância dos princípios constitucionais, no trato de questões controversas trazidas pela sociedade civil, podem relativizar - ou até desconsiderar a literalidade do texto de um artigo, como no caso acima referido.

Disso não se segue que a ideia de cláusulas pétreas, quando referente às proteções dos direitos e garantias individuais, deixe de ser útil ou mostre-se incompatível com as transformações políticas do Estado Democrático de Direito.

É por essa razão que a Constituição e a democracia, enquanto promessa, contêm a radicalidade que abala os horizontes estáveis das nossas expectativas, transgredindo o possível e o concebível, indo além do que é visível e previsível, e que não é propriedade de algum povo escolhido, mas de todos (CHUEIRI, 2013, p. 35).

Uma Constituição sem compromissos significaria, entre outras coisas, uma que não seria capaz de impor limites ao exercício e à expansão do poder, seja o exercido pela soberania popular, seja o por aqueles que se dizem seus representantes, ou seja, dificilmente poderia, em primeiro lugar, ser concebida como Constituição. Se o constitucionalismo representa uma teoria do poder limitado (NEGRI, 1999, p. 10), não seria adequado falar em uma Constituição incapaz de firmar compromissos que transcendam o seu contexto histórico. É nesta direção, em parte, que as cláusulas pétreas adquirem significado e importância.

Cláusulas pétreas não são incompatíveis com as várias manobras e estratégias políticas que questionam e demandam a expansão e fortalecimento dos direitos e garantias individuais, o que representa em muitos casos o núcleo prioritário de várias das demandas dos movimentos sociais. As cláusulas pétreas, que se inscrevem na ordem da polícia, trata-se também de mecanismos presentes na Constituição que visam a resguardar e assegurar as conquistas políticas daqueles movimentos, dificultando o retrocesso em termos de perda dos direitos e garantias individuais conquistados. Representam, em certo sentido, a materialização de um elo institucional entre democracia e constitucionalismo.

\subsection{A DESESTABILIZAÇÃO DO SOCIAL PELA POLÍTICA: PARALELOS COM O PODER CONSTITUINTE}

Seguindo o caminho aberto pelas reflexões do filósofo francês, a ideia de Constituição radical pode hoje ser situada no limiar entre polícia e política, entre a exclusão proporcionada (não apenas) pelos efeitos colaterais do desenvolvimento econômico das 
sociedades capitalistas e a possibilidade de pensarmos uma transcendência na imanência. Essa expressão aparentemente contraditória pode ser compreendida a partir deste trecho:

\begin{abstract}
Uma Constituição radical é aquela que não se conforma aos mecanismos liberais de mútua negociação entre os poderes constituídos, arriscando-se a ser mais do que isso, ou seja, objeto e sujeito da política democrática. Os direitos estão na Constituição, na medida em que ela permite a sua constante reinvenção e demanda (dos direitos). Uma Constituição radical não sintetiza a tensão entre poder constituinte (democracia) e poderes constituídos: ela é precisamente isso, a tensão! (CHUEIRI, 2013, p. 29)
\end{abstract}

A ideia de Constituição demanda um correlato empírico, historicamente situado, caso qualquer direito que nela esteja inserido venha a gozar também de eficácia normativa: uma lei cujo desenvolvimento é fruto de negociações e acordos dos poderes constituídos. Entretanto, constituições, nós insistimos, compõem espaços de possiblidades em que cada direito, preceito ou princípio encontra-se aberto a ser repensado à luz dos eventos, necessidades e problemas contemporâneos: a reinvenção e expansão dos direitos tem início nessa abertura de possibilidades, inscritas no presente, que podem ser atualizadas no futuro. Por isso associamos a Constituição à transcendência: o excesso de significado da Constituição permite a sua constante desestabilização e reformulação, em conformidade com os embates políticos.

Insistir nessa ideia de transcendência implica ressaltar o quanto a Constituição é sempre um projeto, um ato que orienta para um futuro indeterminado e contingente. É essa abertura, a que chamamos de transcendência, que ao mesmo tempo situa historicamente a Constituição, mas impede que ela se vincule ao contexto histórico de sua fundação: sua compreensão é sempre orientada para o futuro ${ }^{5}$. Em outras palavras, a compreensão do significado de uma Constituição, nós assim o entendemos, contempla - mas não se restringe às - especificidades do contexto de sua fundação. Sem dúvida, a Constituição brasileira de 1988 é devedora de e diretamente influenciada por eventos como a abertura democrática e a ainda recente ditadura militar, mas, ao mesmo tempo, enquanto ato institucional, é carregada de uma dimensão performática indeterminada: traduz normativamente os anseios por uma nova ordem social, sem dúvida, mas é uma tradução a ser continuamente negociada por movimentos e instituições.

A imanência a que fizemos alusão visa a impedir a associação de uma concepção que vincula a Constituição a uma espécie de preceito regulador a ser deduzido de uma ordem ideal

\footnotetext{
${ }^{5}$ Esse é um ponto que pode ser desenvolvido por meio de uma leitura cuidadosa do Ser e Tempo de Martin Heidegger, o que em muito ultrapassa as pretensões deste trabalho. Consideramos que uma reflexão acerca da Constituição, sensível ao projeto heideggeriano de uma ontologia fenomenológica, ao menos no que concerne à temporalidade, pode colocar questões do constitucionalismo sob outra perspectiva, talvez mais enriquecedora. (HEIDEGGER, 2005, p. 45 et al.). Para um breve esclarecimento sobre o horizonte de compreensão do ser na obra Ser e Tempo, cf. KOCKELMANS, 1984, p. 47 et al.
}

Revista da Faculdade de Direito - UFPR, Curitiba, vol. 59, n. 3, p. 167-196, 2014. 
e inalcançável. Por conta de uma ênfase que vai recair em certa sensibilidade utópica, perdese toda a dimensão criadora e autônoma do poder constituinte: "É preciso recuperar esta ideia e esta práxis de que o povo, soberano, ao se autolegislar, cria e funda a Constituição, através de toda radicalidade que está em tal ato fundante, impondo a si mesmo as regras e limites que vão regular os seus poderes constituídos" (CHUEIRI, 2013, p. 31).

A relação dinâmica e complexa entre constituinte e constituído se assemelha, em certo sentido, também àquela entre polícia e política. $O$ poder constituinte não se deixa assimilar pelo poder constituído, pois não tem sua origem nele (CHUEIRI, 2013, p. 31). Em contrapartida, uma vez realizado o ato fundante de uma nova ordem constitucional, a implementação do poder constituído inicia todo o jogo de representação política tão característico das democracias modernas. O poder constituinte não desaparece. Antes, é continuamente atualizado, tornando a Constituição simultaneamente retrospectiva e prospectiva, ao reiterar e reafirmar os compromissos estabelecidos, abrindo espaço para a ação política sempre que concretiza e respeita aqueles compromissos (NEGRI, 1999, p. 3 et seq.).

Contrariando o que à primeira vista podemos supor, Rancière não sustenta que a política é independente da polícia, nem que ela algum dia poderá pôr um fím nesta última: política e polícia são essencialmente duas perspectivas diversas em torno da vivência comunitária (RANCIÈRE, 1999, p. 31; TANKE, 2011, p. 51). Os dois segmentos, de fato, encerram lógicas diferentes, porém interligadas: para que aqueles que não são parte reiterem a sua igualdade frente aos que já são parte é necessário primeiramente a manutenção de um regime estético que de antemão determine uma organização social. A lógica da política não é algo que possa ser superada por uma outra que, por sua vez, ao instituir uma suposta igualdade plena, consegue fazer cessar toda e qualquer tensão social. Como ocorre com o poder constituinte, a relação entre política e polícia não é direcionada para uma utopia que estaria prontamente disponível a partir da superação de um polo pelo outro.

Os recentes protestos da sociedade brasileira mostram uma consciência das divisões e conflitos de interesses que não podem ser totalmente resolvidos com apelo à Constituição, ainda que essas mobilizações possam encontrar nela um respaldo jurídico e legítimo de que tanto necessitam. Novamente, a Constituição se situa entre o factual, a ordem instituída, o poder constituído, e o possível, a ruptura, o poder constituinte que, no entanto, é a base para aquele. A fixação dos meios de comunicação de massa nos aspectos violentos e destrutivos dessas mobilizações mostra, no nível cultural, que o protesto, no Brasil, permanece associado ao caos e à violência. Não se torna incomum, portanto, desconsiderar demandas das massas, 
reputando-as como devaneios utópicos e juvenis no tocante ao funcionamento da ordem social. No fim, o próprio termo massa confunde-se com o anonimato, com a falta de nome, este um elemento que caracterizaria aqueles cuja fala é tida como compreensível e relevante perante o poder instituído:

A posição dos patrícios intransigentes é clara: não há espaço para discussão com os plebeus, pela simples razão de que estes não falam. Eles não falam porque são seres sem nome, destituídos do logos - ou seja, de inscrição simbólica na cidade. Plebeus vivem puramente a vida individual que nada deixa para a posteridade exceto a vida, aqui reduzida à sua função reprodutiva. Quem não tem nome não pode falar (RANCIÈRE, 1999, p. 23. Grifos do autor. Tradução livre).

A manutenção do status quo depende do silêncio, da ausência da fala daquele que é excluído quando não se reconhece a sua participação nas questões coletivas da sociedade. A insurgência política do demos, daqueles que não são parte, visa a tornar explícito este dano. A impossibilidade de se circunscrever o poder constituinte a um conjunto de determinações jurídicas é também a impossibilidade de uma ordem social definitiva e completa. Desse ponto decorre que toda e qualquer conquista ou transformação política acabará ignorando alguma demanda ou introduzindo um conjunto de problemas a serem trabalhados posteriormente. É um dos motivos pelos quais a democracia, na concepção de Rancière, está em tensão constante com o aparato institucional: se toda ordem social é sempre precária, insuscetível de abranger e processar todas as demandas presentes e futuras, segue-se que haverá sempre espaços indefinidos e indeterminados, de onde podem surgir novas demandas e antagonismos.

Uma reflexão sobre a Constituição radical não pode deixar de incorporar uma discussão sensível aos quadros de exclusão sistemática presentes em várias sociedades, como a brasileira. Há muitos anos o sociólogo brasileiro Jessé Souza (2006; 2012a; 2012b) vem construindo uma importante e fecunda pesquisa acerca da subcidadania e dos quadros de desigualdade na sociedade brasileira. Essas desigualdades se apresentam em múltiplos segmentos, como na educação, saúde e lazer, criando e reproduzindo um quadro em que expressiva parcela da população carece de meios tangíveis que viabilizem a sua ascensão social e econômica, bem como a sua participação política.

A noção de invisibilidade que, aliás, integra o título de um dos livros de Jessé Souza, A invisibilidade da desigualdade brasileira, precisa ser incorporada à reflexão acerca da Constituição radical, inclusive destacando o papel que esta tem em expandir continuamente as condições que viabilizam um desempenho satisfatório da cidadania para uma parcela cada vez maior de pessoas. Este elemento, por assim dizer, estético, também se mostra presente no pensamento de Rancière, embora sob uma perspectiva teórica bastante diversa. A exclusão 
dos sem-parte é marcada não somente por um distanciamento, geográfico e político, dos centros de tomada de decisão (i. e., do poder), mas por certa invisibilidade que torna suas necessidades e demandas praticamente inexistentes, frente ao aparato institucional da sociedade (TANKE, 2011, p. 49 et seq.).

Ora, como Iris Marion Young (2000 apud BIEST; BINGHAM; RANCIÈRE, 2010, p. 74) bem observou, a legitimidade normativa de qualquer processo democrático de tomada de decisão se encontra intimamente vinculada à inclusão dos que serão potencialmente afetados pelas decisões aí tomadas no próprio processo de deliberação e argumentação. Em outras palavras, os interessados e potencialmente afetados devem estar incluídos nos processos e discussões que levam à tomada de determinada decisão em detrimento de outra.

A primeira subseção buscou compatibilizar o poder constituinte com o poder constituído - um passo fundamental para que possamos pensar uma Constituição radical sem que a limitação do poder político, crucial para a própria história do constitucionalismo, tornese um obstáculo. No entanto, essa compatibilização precisa evitar o equívoco da teoria constitucional, mencionado por Vera Karam, de limitar ou circunscrever o poder constituinte ao constituído, e por isso buscamos mostrar como o primeiro não se reduz, nem é determinado, pelo segundo. A tensão entre os dois polos é elaborada sob o pano de fundo de uma reflexão acerca da temporalidade da Constituição. Esta firma compromissos no presente que devem ser observados no futuro, caso pretendam para si qualquer relevância.

Compromissos buscam introduzir certas determinações sobre um futuro contingente e imprevisível: sem eles, no entanto, a ideia historicamente consolidada de Constituição perde seu significado. Como novos antagonismos e demandas podem surgir dos mais variados âmbitos do social, muitos deles podem se chocar com os compromissos firmados. Ao menos dois percursos podem ser vislumbrados de imediato: (1) uma vez que se chocam com os compromissos firmados, as novas demandas ou antagonismos podem ser juridicamente ignorados: seus membros deverão esperar acumular capital político suficiente para que consigam propor mudanças jurídicas significativas; (2) os compromissos devem ser repensados à luz das circunstâncias particulares.

Para ilustrar esse ponto, utilizamos como exemplo as cláusulas pétreas, como mecanismos que, situados na tensão entre presente e futuro, são capazes de sustentar os compromissos sem comprometer ou obstruir transformações sociais significativas. A proteção dos direitos fundamentais e garantias individuais, por exemplo, dentro da estrutura formal da Constituição, pode ser importante para obstruir mobilizações que busquem subtrair ou tornar inefetivos os direitos das minorias políticas que se tornaram também fundamentais. 


\section{CONSIDERAÇÕES FINAIS}

O propósito deste artigo consistiu em construir um diálogo com a proposta apresentada por Vera Karam de Chueiri em torno da ideia de Constituição radical. Como pretendemos sustentar neste trabalho, essa ideia introduz uma série de questionamentos que não são habitualmente levantados no domínio do direito ou da teoria constitucional brasileira, ambos marcadamente liberais.

Sustentamos que a obra do filósofo francês Jacques Rancière pode sim fornecer alguns conceitos e noções que enriquecem a reflexão na direção que propõe Vera Karam, dentre eles o par polícia/política e a reformulação que se faz do significado de democracia. As noções mencionadas nos ajudam a observar como a ideia de democracia permanece sendo restrita e adequada às formas de regimes políticos tecnocráticos, que restringem a participação popular a um mínimo de atividades quase ritualizadas, ao mesmo tempo que é associada a uma forma de governo voltada para o povo.

Em seu trabalho La haine de la démocratie, Rancière aponta como, por trás do discurso que celebra a superioridade da democracia perante os outros modelos que se buscou implementar (como os dos países socialistas), existe um outro discurso de ódio e aversão ao excesso de liberdade de que gozam os cidadãos. Valores tradicionais são contestados, ações afirmativas e medidas de redistribuição de riquezas são implementadas, protestos e passeatas perturbam a ordem comum das coisas ${ }^{6}$.

Os conceitos de agonismo e antagonismo, extraídos da obra de Chantal Mouffe, tornam-se frutíferos no trato da temática que Vera Karam desenvolve em seu artigo. Nem todo conflito envolve a eliminação do outro, concebendo-o como o inimigo a ser erradicado. É possível, dentro de uma relação agonística, assumir a incompatibilidade de visões de mundo ao mesmo tempo que respeitam-se algumas regras e princípios básicos que tornem esse tipo de relação viável. Não deixa de ser viável que a Constituição, em especial no que concerne aos direitos individuais e às garantias fundamentais, possa integrar aquele repertório de regras a ser respeitado pelas partes, ainda que objeto de interpretações políticas conflitantes. Parecenos que essa é uma forma adequada de relacionar diretamente democracia, conflito e Constituição, sem reduzir - ou fundar - um termo sobre o outro.

\footnotetext{
${ }^{6}$ Como exemplo, basta observamos certos eventos da recente história brasileira, que envolvem mobilizações populares expressivas, desde os movimentos de junho de 2013 até os rolezinhos, eventos estes que expressam as potências implícitas da população, capazes de transformar e desestabilizar a política institucionalizada quando esta persiste em alienar e atuar contra os interesses da população. A ideia de Constituição radical precisa assimilar essas tensões mediante uma perspectiva que compreenda o papel construtivo do conflito na vivência democrática.
} 
Em contrapartida, sendo, talvez, esse um ponto estranho ao que pensam Negri e Rancière, a busca por uma maior concretização das normas jurídicas constitucionais pode ser de grande auxílio na manutenção de um espaço de contestação e divergência que continuamente revitaliza a democracia. Longe de sequer considerarmos resolver a tensão muito complexa entre democracia e constitucionalismo, pretendemos apenas apontar a negociação contínua e indeterminada que precisa haver entre os dois polos na reflexão acerca da Constituição radical (CHUEIRI, 2013, p. 31).

\section{REFERÊNCIAS}

BIEST, Gert; BINGHAM, Charles; RANCIÈRE, Jacques. Jacques Rancière: Education, Truth, Emancipation. London and New York: Continuum, 2010.

BRASIL. Constituição da República Federativa do Brasil de 1988. Diário Oficial da República Federativa do Brasil, Brasília, DF, 05 out 1988. Disponível em: $<$ http://www.planalto.gov.br/ccivil_03/constituicao/Constituicao.htm $>$. Acesso em: 5 jul. 2014.

CHUEIRI, Vera Karam de. Constituição radical: uma ideia e uma prática. Revista da Faculdade de Direito UFPR, Curitiba, n. 58, p. 25-36, 2013.

CORCORAN, Steven. Editor's Introduction. In: RANCIÈRE, Jacques; CORCORAN, Steven. Dissensus - On Politics and Aesthetics. London and New York: Continuum, p. 1-24, 2010.

GADAMER, Hans-Georg. Verdade e Método I: traços fundamentais de uma hermenêutica filosófica. 7. ed. Petrópolis: Vozes, 2005.

HEIDEGGER, Martin. Ser e Tempo (Parte I). 15. ed. Petrópolis: Vozes, 2005.

HEMEL, Ernst Ban Den. Included but not Belonging - Badiou and Rancière on Human Rights. Krisis - Journal for Contemporary Philosophy, Netherlands, n. 3, p. 16-30, 2008.

KOCKELMANS, Joseph J. On the Truth of Being - Reflections on Heidegger's Later Philosophy. Bloomington: Indiana University Press, 1984.

MALIK, Suhail; PHILLIPS, Andrea. The Wrong of Contemporary Art: Aesthetics and Political Indeterminacy. In: BOWMAN, Paul; STAMP, Richard (Org.). Reading Rancière Critical Dissensus. London: Continuum Press, p. 111-28, 2011.

MAUS, Ingeborg. O Judiciário como superego da sociedade: o papel da atividade jurisprudencial na "sociedade órfã". Revista Novos Estudos CEBRAP. São Paulo, n. 58, p. 183-202, nov. 2002.

MAY, Todd. The Political Thought of Jacques Rancière - Creating Equality. Edinburgh: Edinburgh University Press, 2008. 
MOUFFE, Chantal. On the Political. London and New York: Routledge, 2005.

. The Democratic Paradox. London: Verso, 2000.

. The Return of the Political. London: Verso, 1993.

NEGRI, Antonio. Insurgencies: Constituent Power and the Modern State. Minneapolis and London: University of Minnesota Press, 1999.

RANCIÈRE, Jacques. Democracies against Democracy - An Interview with Eric Hazan. In: AGAMBEN, Giorgio et al. (Org.). Democracy in What State? New York: Columbia University Press, p. 76-81, 2011.

. Disagreement - Politics and Philosophy. Minneapolis and London: University of Minnesota Press, 1999.

Hablar de crisis de la sociedad es culpar a sus víctimas. Público.es, 2012. Disponível em: <http://www.publico.es/culturas/416926/hablar-de-crisis-de-la-sociedad-esculpar-a-sus-victimas $>$. Acesso em: 1 ago. 2014.

. Hatred of Democracy. 2. ed. London: Verso, 2009.

Ten Theses on Politics. In: RANCIÈRE, Jacques; CORCORAN, Steven. Dissensus On Politics and Aesthetics. London and New York: Continuum, p. 27-44, 2010.

SOUZA, Jessé. A construção social da subcidadania - Para uma sociologia política da modernidade periférica. 2. ed. Belo Horizonte: Editora UFMG, 2012 b.

. A invisibilidade da desigualdade brasileira. Belo Horizonte: Editora UFMG, 2006.

. Os batalhadores brasileiros: nova classe média ou nova classe trabalhadora? Belo Horizonte: Editora UFMG, 2012a.

TANKE, Joseph J. Jacques Rancière: An Introduction. London and New York: Continuum Publishing, 2011.

WATKIN, Christopher. Paul Ricoeur: Justice. In: WATKIN, Christopher. Phenomenology or Deconstruction? - The Question of Ontology in Maurice Merleau-Ponty, Paul Ricoeur and Jean-Luc Nancy. Edinburgh: Edinburgh University Press, p. 106-35, 2009.

\section{THE CONSTITUTIONALISM THROUGH THE CONFLICT - A REFLECTION AND A FEW REMARKS REGARDING THE IDEA OF RADICAL CONSTITUTION}

ABSTRACT: This article intends to discuss and develop some points regarding the idea of radical Constitution, introduced by Vera Karam de Chueiri in her article Radical Constitution: an idea and a practice. Taking a few concepts from Jacques Rancière's work, we emphasize how that concept of Constitution could develop a positive relation with political conflicts without risking the many achievements of social movements and the rights of political minorities. Finally, we discuss how the idea of radical Constitution could be productive in Revista da Faculdade de Direito - UFPR, Curitiba, vol. 59, n. 3, p. 167-196, 2014. 
thinking the complex, difficult interdependence between constitutionalism and democracy, something that is also crucial for Chueiri's work.

KEYWORDS: Agonism. Constitutionalism. Democracy. Rancière.

Recebido: 18 de julho de 2014

Aprovado: 10 de outubro de 2014 